\title{
Socioeconomic-related inequalities in self-rated health status in Kermanshah city, Islamic Republic of Iran: a decomposition analysis
}

\author{
Satar Rezaei, ${ }^{1}$ Mohammad Hajizadeh, ${ }^{2}$ Sina Ahmadi ${ }^{1}$, Ali Kazem Karyani, ${ }^{1}$ Masoud Khosravipour, ${ }^{3}$ Farid Khosravi $^{3}$ and Arman Latifi $^{4}$
}

${ }^{1}$ Research Center for Environmental Determinants of Health, Health Institute, Kermanshah University of Medical Sciences, Kermanshah, Islamic Republic of Iran. ${ }^{2}$ School of Health Administration, Faculty of Health, Dalhousie University, Halifax, Canada. ${ }^{3}$ Student Research Committee, Kermanshah University of Medical Sciences, Kermanshah, Islamic Republic of Iran. ${ }^{4}$ Department of Public Health, Maragheh University of Medical Sciences, Maragheh, Islamic Republic of Iran. (Correspondence to: Arman Latifi: latifiarman@gmail.com).

\begin{abstract}
Background: Socioeconomic-related inequalities in health are a major public health challenge in both developed and developing countries. Little evidence is available on socioeconomic-related inequalities in health in different regions of the Islamic Republic of Iran.
\end{abstract}

Aims: This study aimed to determine socioeconomic-related inequality in poor self-rated health in adults in Kermanshah city, western Islamic Republic of Iran.

Methods: This cross-sectional study with stratified sampling obtained data on socioeconomic status, demographic characteristics, behavioural risk factors and self-rated health of 2040 adults ( $\geq 18$ years) in Kermanshah city. A self-administrated questionnaire was used to collect data from the participants. The concentration (C) index and C curve were used to determine the socioeconomic-related inequality in poor self-rated health. A decomposition analysis of the $C$ index was done to identify the factors explaining socioeconomic-related inequality in poor self-rated health.

Results: The crude and age-adjusted prevalence of poor self-rated health was $13.8 \%$ and $18.1 \%$, respectively. The estimated C for the whole sample was -0.295 , indicating that poor SRH was concentrated in the poor. The decomposition results suggested that socioeconomic status $(45.5 \%)$, having a chronic health condition $(11.9 \%)$ and smoking $(7.3 \%)$ were the main factors contributing to the concentration of poor self-rated health among those of lower socioeconomic status.

Conclusion: The concentration of poor self-rated health among the poor in Kermanshah city warrants policy attention. Policies aimed at reducing inequality in wealth distribution and risky health behaviour and preventing chronic health conditions among the poor may mitigate socioeconomic-related inequalities in poor self-rated health in Kermanshah.

Keywords: Self-rated health, socioeconomic inequalities, decomposition analysis, Islamic Republic of Iran

Citation: Rezaei S; Hajizadeh M; Ahmadi S; Kazem Karyani A; Khosravipour M; Khosravi F et al. Socioeconomic-related inequalities in self-rated health status in Kermanshah city, Islamic Republic of Iran: a decomposition analysis. East Mediterr Health J. 2020;26(7):820-827. https://doi.org/10.26719/ emhj.20.001

Received: 25/04/18; accepted: 14/10/18

Copyright (C) World Health Organization (WHO) 2020. Open Access. Some rights reserved. This work is available under the CC BY-NC-SA 3.0 IGO license (https://creativecommons.org/licenses/by-nc-sa/3.o/igo)

\section{Introduction}

The overall health status of the general population worldwide has improved significantly in the 21st century. However, in spite of this improvement and the increasing resources spent on health care services globally, socioeconomic-related inequalities in health are one of the main public health challenges (1-4) and reducing such inequalities is a key priority in both developed and developing countries (5). It has been widely argued that socioeconomic differences can lead to inequalities in health status in society through inequalities in resources and access to material opportunities such as employment, continuing education, nutrition and housing $(6,7)$.

Self-rated health (SRH) is a comprehensive measure of people's well-being and quality of life (8). It is a singleitem measure where respondents are asked to assess and rate their own health status (9). SRH is a well-validated and commonly-used measure of health status (10), which is associated with several factors, including sociodemographic status, economic status, and behavioural, psychosocial and chronic health conditions. Understanding and identifying the main factors affecting SRH are needed to explain variations in $\mathrm{SRH}$, and thus suggest strategies to improve SRH in different social groups (11-13).

To date, several studies have reported socioeconomic inequalities in various indicators of health in the Islamic of Iran $(2,14)$ and worldwide $(8,15,16)$. However, to the best our knowledge, there is little evidence on socioeconomicrelated inequalities in health in different regions of the Islamic Republic of Iran (2), and no study has measured and done a decomposition analysis of socioeconomic-related inequality in SRH in western Islamic Republic of Iran. To fill this gap in the literature, we used the concentration index approach to measure socioeconomic-related inequalities in poor-SRH in adults aged 18 years and older in Kermanshah city. We also did a decomposition analysis of socioeconomic inequality in poor SRH to determine key factors that explain the observed inequality in health. Measuring and monitoring social inequalities in health can provide useful information to identify effective interventions to reduce these inequalities in different subgroups of the population, especially vulnerable subgroups (17). 


\section{Methods}

\section{Study setting}

This study was carried out in Kermanshah city, western Islamic Republic of Iran from January to April 2018. The population of the Kermanshah province was estimated to be approximately one million in 2016 (18).

\section{Study population, sample size and sampling method}

This was a cross-sectional study using data on socioeconomic status, demographic characteristics, behaviour (smoking and obesity) and SRH of 2040 adults (aged 18 years and more) in Kermanshah city. Multistage sampling was used to select the study participants. We first divided Kermanshah city into five areas (strata) of central, western, eastern, southern and northern; then an equal number of participants was selected from each area. Because of funding constraints, a convenience sampling method was used to select study participants.

The following formula was used to calculate the sample size: $n=z^{2}(p(1-p)) / \mathrm{d}^{2}$, where $z=1.96(95 \%$ level of significance), $p=$ prevalence of poor SRH and $d=$ precision, set at 0.5 and 0.03 , respectively. The final calculated sample size was 1537 . We added $35 \%$ to the required sample size to increase the power of the study.

\section{Data collection and variables}

A self-administrated questionnaire was used for data collection. The questionnaire consisted of questions on age, sex, marital status, years of education, health insurance coverage, presence of chronic health condition(s), SRH, smoking behaviour, obesity status and household durable assets - number of rooms per capita, type of house ownership, house size (number of square metres), ownership of a car, computer/laptop, freezer, dishwasher and television, and access to the Internet. The outcome variable, poor SRH, was measured using the question: "How do you rate your current general health status?" Response choices were on a five-point Likert scale: $5=$ very good, 4 = good, $3=$ moderate, $2=$ poor and $1=$ very poor. Similar to previous studies $(2,19,20)$, participants were classified as having poor SRH if they rated their health status poor or very poor. The reliability of this categorization was 0.85 based on the intraclass correlation coefficient.

\section{Statistical analysis}

The frequency and 95\% confidence interval (CI) were used to present descriptive characteristics of study population and the crude and age-adjusted prevalence of poor $\mathrm{SRH}$, respectively.

The concentration $(C)$ index and $C$ curve were used to measure and illustrate socioeconomic-related inequalities in poor SRH $(21,22)$. The $C$ curve plots the cumulative percentage of the outcome variable (poor SRH) on they-axis against the cumulative percentage of the respondents ordered by socioeconomic status on the $\mathrm{x}$-axis. If the $\mathrm{C}$ curve lies above the 45-degree line of perfect equality, poor $\mathrm{SRH}$ is concentrated in the poorer people; if the $C$ curve lies the below the 45-degree line of perfect equality, poor SRH is concentrated in the wealthier people. The $C$ index is defined as twice the area between the 45 -degree line and the $C$ curve. The index ranges between -1 and +1 , with zero indicating perfect equality. A negative value for the index suggests that the outcome variable (poor SRH) is more prevalent in poorer people. A positive value for the index suggests that poor SRH is more prevalent in richer people. The $C$ index was estimated using the following convenient regression formula (22). As poor SRH is a binary variable, as per Wagstaff (23), we normalized $C$ by multiplying the index by $1 /(1-\mu)$ (i.e. $\left.C_{n}=C /(1-\mu)\right)$ where $\mu$ is the mean (proportion) of poor SRH for the sample.

We used the principal component analysis technique to construct the socioeconomic status score of participants (24). We included years of schooling, number of foreign and domestic trips, income and ownership of durable assets (number of rooms per capita, type of house ownership, house size per square metre, possession of a mobile telephone, access to the Internet, and ownership of a car, television, computer/ laptop, freezer, dishwasher, microwave and vacuum cleaner) in the principal component analysis. The socioeconomic status scores obtained from the principal component analysis were used to rank the respondents in the computation of $C$ index.

We did a decomposition analysis of the $C$ index to identify the contribution of each explanatory variable to the socioeconomic-related inequality in poor SRH (25). If the linear regression relates the outcome variable $y$ (poor SRH) to a set of explanatory variables, $x_{k}$ as follows:

$y=\alpha+\sum_{k} \beta_{k} x_{k}+\varepsilon$

then $C_{n}$ for poor SRH can be decomposed using the following equation:

$C_{n}=\frac{C}{1-\mu}=\frac{\sum_{k}\left(\frac{\beta_{k} \bar{x}_{k}}{\mu}\right)_{C_{k}}}{1-\mu}+\frac{G C_{\varepsilon}}{\frac{\mu}{1-\mu}}$

where the $C_{n}$ is the concentration index for poor SRH, $\bar{x}_{k}$ is the mean of each determinant, and $C_{k}$ and $\beta_{k}$ are the concentration index and coefficient for the explanatory variables, respectively.

The component $\frac{\beta_{k} \bar{x}_{k}}{\mu}$ shows the elasticity of poor SRH with regard to the explanatory variables.

$\sum_{k}\left(\frac{\beta_{k} \bar{x}_{k}}{\mu}\right) C_{k}$ shows the contribution of factor $\bar{x}_{k}$ to $C_{n}$ for poor SRH. A negative (positive) absolute contribution of an independent factor to $C_{n}$ suggests that socioeconomic-related variation of the factor $C_{k}$ and the relationship between the independent factor and poor SRH contributes to the concentration of poor SRH in the poor (rich). $G C_{e} / \mu$ denotes the residual component and reflects the socioeconomic-related inequality in poor SRH that cannot be explained by the explanatory variables included in the model. As poor SRH is a binary variable, the marginal effects obtained from a logit model were used in the decomposition analysis. 
STATA version 14.2 software was used for all data analyses.

\section{Ethical considerations}

Verbal consent was obtained from each participant after explaining the purpose of the study. All the participants were also informed that they had the right to withdraw from the data collection process at any point. Those who did not provide consent to participate were excluded from the survey. Data were collected anonymously and were only used for research purpose. The study was approved by the Ethics Review Committee of the Deputy of Research at Kermanshah University of Medical Sciences (KUMS) (IR.KUMS.REC.1396.714).

\section{Results}

A total of 2040 adults, aged 18 years and more, participated in the study (no one declined to participate). The mean age was 36.5 years (standard deviation $=12.4$ ). Table 1 summarizes the characteristics of the adult participants and the prevalence of poor SRH according to sociodemographic, socioeconomic and behavioural characteristics in adults in Kermanshah city. As shown in Table 1, 1247 (61.1\%) of the sample were men. Most (1622, 79.5\%) of the sample had health insurance coverage; $267(13.1 \%)$ of the sample had a chronic health condition, and 379 (18.6\%) were current smokers. Of the total sample, 283 respondents - 13.9\% (95\% confidence interval (CI): $12.4-15.4 \%$ ) - rated their health status as poor or very poor. The prevalence of poor SRH adjusted for age was $18.1 \%$ (95\% CI: 16.0-20.3\%). The crude and adjusted prevalence of poor SRH in participants with a chronic health condition was $8.5 \%$ (95\% CI: 7.3-9.9) and $11.4 \%$ (95\% CI: 9.4-13.9), respectively.

The results of the principal component analysis suggest that the first principal component explained most of the variation (24.1\%). Thus, we used scoring factors of the first principal component to construct the socioeconomic status score of participants. Based on the estimated socioeconomic status scores using the principal component analysis technique, we categorized participants into five socioeconomic status groups (quintiles) from poorest (first quintile) to richest (fifth quintile). The crude and adjusted prevalence of poor SRH for the lowest socioeconomic status quintile were $28.2 \%$ (95\% CI: $24.0-32.8 \%$ ) and $28.9 \%$ (95\% CI: $24.8-33.4 \%$ ), respectively. The corresponding figures for the highest socioeconomic status quintile were $6.4 \%$ (95\% CI: $4.4-$ $9.2 \%$ ) and $9.7 \%$ (95\% CI: 7.1-13.0\%), respectively.

Table 2 shows the $C$ indexes for the whole sample and by sex. The $C$ index for the whole sample was -0.295 . The $C$ indexes for males and females were -0.223 and -0.377 , respectively. These results illustrated that poor SRH is concentrated in poorer people $(P<0.001)$. In addition, the $C$ curves of poor SRH lay above the line of perfect equality, indicating that poor SRH was more prevalent in socioeconomically disadvantaged adults (Figure 1).

The results of the decomposition analysis of the $C$ index for poor SRH are shown in Table 3. The estimated
Table 1 Prevalence of poor self-rated health (SRH) according to characteristics of the participants, Kermanshah, Islamic Republic of Iran, 2017

\begin{tabular}{|c|c|c|c|}
\hline \multirow{2}{*}{ Characteristic } & \multirow{2}{*}{$\begin{array}{c}\text { No. (\%) } \\
(n=2040)\end{array}$} & \multicolumn{2}{|c|}{ Prevalence of poor SRH (\%) } \\
\hline & & Crude $(95 \%$ CI) & $\begin{array}{c}\text { Age-adjusted } \\
\text { (95\% CI) }\end{array}$ \\
\hline \multicolumn{4}{|l|}{ Age group (years) } \\
\hline$<40$ & $1326(65.0)$ & $7.8(6.4-9.4)$ & $8.1(6.6-9.6)$ \\
\hline$\geq 40$ & $714(35.0)$ & $25.2(22.1-28.5)$ & $27.3(23.6-31.3)$ \\
\hline \multicolumn{4}{|l|}{ Sex } \\
\hline Male & $1247(61.1)$ & $11.6(8.6-9)$ & $13.8(8.4-8.8)$ \\
\hline Female & $793(38.9)$ & $17.4(14.9-20.2)$ & $25.2(22.1-28.6)$ \\
\hline \multicolumn{4}{|l|}{ Marital status } \\
\hline Single & $717(35.1)$ & $5.7(4.2-7.7)$ & $10.7(8.6-13.2)$ \\
\hline Married & $1215(59.6)$ & $17.5(15.5-19.7)$ & $18.1(15.8-20.6)$ \\
\hline Divorced/widowed & $108(5.3)$ & $26.8(19.2-36.1)$ & $18.2(15.1-21.8)$ \\
\hline \multicolumn{4}{|l|}{ Socioeconomic status } \\
\hline 1 (poorest) & $408(20.0)$ & $28.2(24-32.8)$ & $28.9(24.8-33.4)$ \\
\hline 2 & $409(20.1)$ & $11.2(8.5-14.7)$ & $13.4(10.7-17.8)$ \\
\hline 3 & $407(20.0)$ & $12.8(9.8-16.4)$ & $16.9(13.4-21.1)$ \\
\hline 4 & $408(20.0)$ & $10.8(8.1-14.2)$ & $19.2(16.3-22.5)$ \\
\hline 5 (wealthiest) & $408(20.0)$ & $6.4(4.4-9.2)$ & $9.7(7.1-13)$ \\
\hline \multicolumn{4}{|l|}{ Health insurance } \\
\hline Yes & $1622(79.5)$ & $13.6(12.4-15.4)$ & $17.4(15.2-19.9)$ \\
\hline No & $418(20.5)$ & $14.8(11.7-18.6)$ & $19.3(16.1-23)$ \\
\hline \multicolumn{4}{|l|}{ Smolking status } \\
\hline Smoker & $379(18.6)$ & $17.9(14.4-22.1)$ & $16.7(13.1-21)$ \\
\hline Non-smoker & $1661(81.4)$ & $12.9(11.4-14.6)$ & $19.6(17.3-22.2)$ \\
\hline \multicolumn{4}{|l|}{ Obesity status } \\
\hline Obese & $178(8.7)$ & $28.1(21.9-35.2)$ & $30.2(25.7-35.1)$ \\
\hline Not obese & $1862(91.3)$ & $12.5(11.1-14.1)$ & $16.7(14.5-19.1)$ \\
\hline \multicolumn{4}{|c|}{ Chronic health condition } \\
\hline Yes & $267(13.1)$ & $49.4(43.4-55.4)$ & $45.6(40.3-51)$ \\
\hline No & $1773(86.9)$ & $8.5(7.3-9.9)$ & $11.4(9.4-13.9)$ \\
\hline
\end{tabular}

CI: confidence interval.

marginal effects obtained from model estimations suggest that lower socioeconomic status, being female, lack of health insurance, being married, presence of a chronic health condition, smoking and obesity were associated with higher probability of poor SRH. The $C$ index for the explanatory variables shows that adults aged 40 years and older $(C=-0.041)$, those who were married $(C=-0.049)$, smokers $(C=-0.216)$ and those with a chronic health condition $(C=-0.035)$ were more likely to be poor. On the other hand, people with health

Table 2 Normalized concentration index for poor self-rated health in Kermanshah, Islamic Republic of Iran, 2017

\begin{tabular}{|lccc|} 
Sample & $\begin{array}{c}\text { Concentration } \\
\text { index }\end{array}$ & $\begin{array}{c}\text { 95\% confidence } \\
\text { interval }\end{array}$ & P-value \\
\hline Male & -0.223 & -0.320 to -0.126 & $<0.001$ \\
Female & -0.377 & -0.477 to -0.276 & $<0.001$ \\
\hline Total & -0.295 & -0.365 to -0.225 & $<0.001$ \\
\hline
\end{tabular}


Figure 1 Concentration curve for poor self-rated health (SRH) in men, women and in the total sample
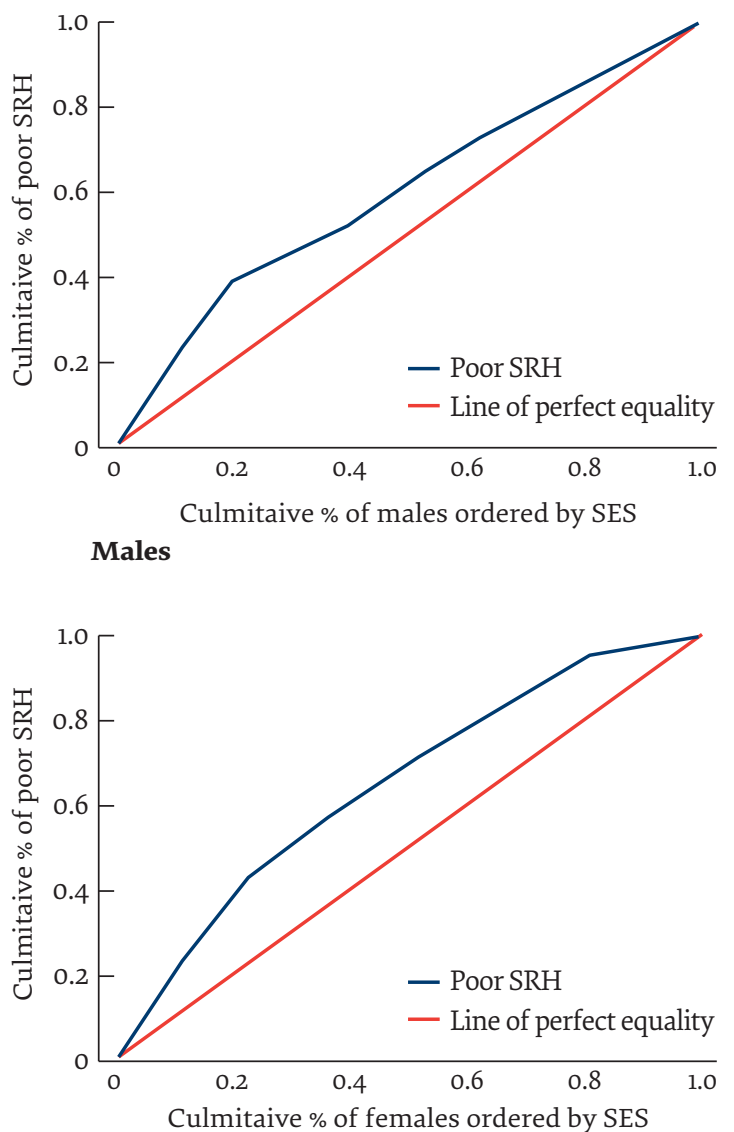

Females

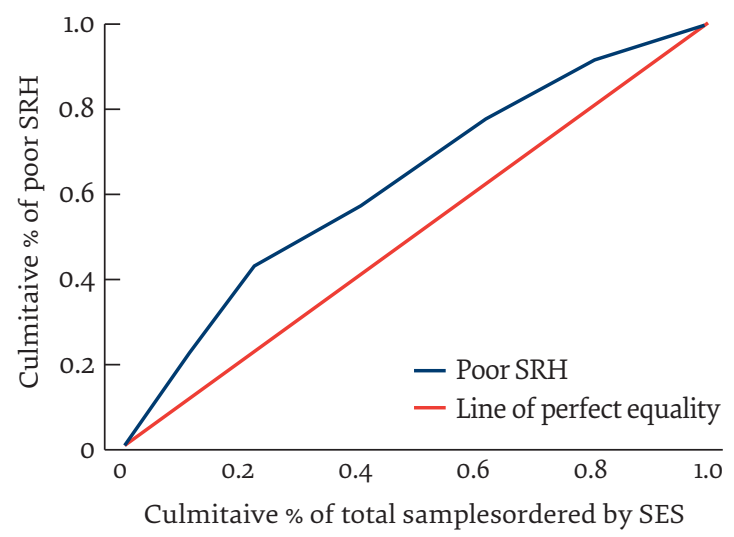

Total

insurance coverage $(C=0.051)$ and obese adults $(C=$ 0.135) were more concentrated in the better-off. The total contribution percentage for each determinant is given in the last column of Table 3, which shows that the main factors contributing to socioeconomic-related inequality in poor SRH were socioeconomic status (45.50\%), having a chronic health condition $(11.90 \%)$ and smoking status (7.26\%). The results suggest that $47.70 \%$ of socioeconomicrelated inequality in poor SRH is explained by the determinants included in the study and the remaining of $52.30 \%$ is explained by the residuals (i.e. variables not included in our decomposition model).

\section{Discussion}

The findings of our study show that poor SRH was higher in women than men. A higher proportion of poor SRH in women compared with men was found in studies in China (26), Greece (27) and Syria (16). The reported prevalence of poor SRH in the literature varies widely, ranging from $7 \%$ to $80 \%(2,8,16,28-30)$. For example, according to the 2008 Turkish Health Survey, $7 \%$ of men assessed their general health status as poor (8). The prevalence of poor SRH in adults was $9.1 \%$ in a study similar to ours in Syria (16). In contrast, a study in the Islamic Republic of Iran reported that $80 \%$ of women rated their health as poor (29). One of the possible explanations for this discrepancy could be because of demographic, cultural and regional differences in reporting general health status (31).

Our findings indicate that some socioeconomic and behavioural characteristics were statistically significantly associated with poor SRH. Age, sex, smoking status, obesity, the presence of a chronic health condition and socioeconomic status of individuals were the main predictors of poor SRH. We found that lower socioeconomic status was associated with a higher prevalence of poor SRH in our sample. This may be because rich people have access to better nutrition and health care services compared with poor people. Studies in other countries also show a negative correlation between socioeconomic status and poor SRH $(2,26,32)$. In our study, being female was associated with a higher probability of poor SRH. These findings are consistent with other studies that reported the prevalence of poor SRH in women and men $(2,8,28,29,33,34)$.

Similar to other studies, we found a higher prevalence of poor SRH in older adults $(2,13,16,35)$. In addition, poor SRH was significantly associated with smoking and having a chronic disease in our study and other studies $(8,29)$.

Poor SRH was more prevalent in individuals of lower socioeconomic status in our study. Similarly, a study in Turkey in 2012 found that the $\mathrm{C}$ index for poor SRH was -0.15 indicating a clear inequality in SRH with those categorized as poor more likely to have poor SRH (8). Another study in China found a similar inequality in SRH (26), and a study in Tehran also showed that poor SRH was more prevalent in poor people (2).

Our decomposition analysis of socioeconomic-related inequality in poor SRH showed that socioeconomic status, the presence of a chronic health condition and smoking status were the main contributors to socioeconomicrelated inequality in health in Kermanshah city. While lower socioeconomic status and presence of chronic health condition increased the concentration of poor SRH in poor people, a higher prevalence of obesity in the rich increased the concentration of poor SRH in the rich. These findings are consistent with the results of other studies that reported socioeconomic status as the most important factor contributing to socioeconomic inequality in health $(14,36,37)$. For example, the study in Tehran found that economic status $(47.8 \%)$, level of education $(29.2 \%)$ and age $(23.0 \%)$ were the main 


\begin{tabular}{|c|c|c|c|c|c|c|c|}
\hline \multirow[t]{2}{*}{ Variable } & \multirow{2}{*}{$\begin{array}{c}\text { Marginal } \\
\text { effects }\end{array}$} & \multirow[t]{2}{*}{ Mean } & \multirow[t]{2}{*}{ Elasticity } & \multirow[t]{2}{*}{$C_{\mathbf{k}}$} & \multicolumn{3}{|c|}{ Contribution } \\
\hline & & & & & Absolute & Percentage & $\begin{array}{l}\text { Summed } \\
\text { percentage }\end{array}$ \\
\hline \multicolumn{8}{|l|}{ Age group (years) } \\
\hline$<40$ & Ref & 0.65 & Ref & Ref & Ref & Ref & 2.4 \\
\hline$\geq 40$ & 0.069 & 0.35 & 0.174 & -0.041 & -0.007 & 2.4 & \\
\hline \multicolumn{8}{|l|}{ Sex } \\
\hline Male & Ref & 0.61 & Ref & Ref & Ref & Ref & 0.27 \\
\hline Female & 0.040 & 0.39 & 0.112 & -0.007 & -0.000 & 0.27 & \\
\hline \multicolumn{8}{|l|}{ Marital status } \\
\hline Single & Ref & 0.35 & Ref & Ref & Ref & Ref & 2.56 \\
\hline Married & 0.032 & 0.60 & 0.138 & -0.049 & -0.007 & 2.31 & \\
\hline Divorced/widowed & 0.011 & 0.05 & 0.004 & -0.168 & -0.000 & 0.23 & \\
\hline \multicolumn{8}{|l|}{ Socioeconomic status } \\
\hline 1 (poorest) & 0.124 & 0.20 & 0.179 & -0.800 & -0.143 & 48.5 & 45.50 \\
\hline 2 & 0.029 & 0.21 & 0.044 & -0.399 & -0.017 & 5.9 & \\
\hline 3 & 0.065 & 0.19 & 0.088 & 0.000 & 0.000 & 0.00 & \\
\hline 4 & 0.046 & 0.20 & 0.066 & 0.400 & 0.026 & -9.00 & \\
\hline 5 (wealthiest) & Ref & 0.20 & Ref & Ref & Ref & Ref & \\
\hline \multicolumn{8}{|l|}{ Health insurance } \\
\hline Yes & 0.14 & 80 & 0.081 & 0.051 & 0.004 & -1.40 & -1.40 \\
\hline No & Ref & 20 & Ref & Ref & Ref & Ref & \\
\hline \multicolumn{8}{|l|}{ Smoking status } \\
\hline Smoker & 0.017 & 0.81 & 0.099 & -0.216 & -0.021 & 7.26 & 7.26 \\
\hline Non-smoker & Ref & 0.19 & Ref & Ref & Ref & Ref & \\
\hline \multicolumn{8}{|l|}{ Obesity status } \\
\hline Obese & 0.069 & 0.91 & 0.453 & 0.135 & 0.061 & -20.72 & -20.72 \\
\hline Not obese & Ref & 0.9 & Ref & Ref & Ref & Ref & \\
\hline \multicolumn{8}{|l|}{ Chronic health condition } \\
\hline Yes & 0.300 & 0.13 & 0.281 & -0.035 & -0.035 & 11.90 & 11.90 \\
\hline No & Ref & 0.87 & Ref & Ref & Ref & Ref & \\
\hline Total observed & & & & & -0.141 & & 47.7 \\
\hline Residual & & & & & -0.154 & & 52.3 \\
\hline C index for total sample & & & & & -0.295 & & 100 \\
\hline
\end{tabular}

$C_{k}$ : concentration index, Ref: reference category in the regression analysis.

determinants of socioeconomic inequality in SRH (2). The study in Turkey also suggested education level (70.7\%) and household wealth (9.7\%) were the two main contributing factors to inequality in SRH (8).

Our study has some limitations that should be considered when interpreting the findings. First, we used a convenience sampling method to select study participants in Kermanshah city. Thus, the generalizability of our findings may be limited. Second, although SRH status is a valid measure of health status (10), participants may have interpreted the question on $\mathrm{SRH}$ differently and therefore we should be aware of the potential problem of using poor SRH to measure inequality in health. Third, our study was cross-sectional and therefore we cannot establish causal relationships between the determinants of socioeconomic inequality in health and poor SRH in our decomposition analysis.

\section{Conclusion}

Socioeconomic status of adults, the presence of a chronic health condition and smoking were the largest contributors to socioeconomic inequality in poor SRH. Thus, policies aimed at reducing smoking and preventing chronic diseases among poorer people may mitigate some of the socioeconomic inequalities in poor SRH in Kermanshah. 


\section{Acknowledgement}

We thank the Research Council of Kermanshah University of Medical Sciences.

Funding: The study was funded by the Research Deputy of Kermanshah University of Medical Sciences (Grant number: 97090).

Competing interests: None declared.

\section{Inégalités socio-économiques liées à l'état de santé auto-évalué dans la ville de Kermanshah (République islamique d'Iran) : une analyse de décomposition}

\section{Résumé}

Contexte : Les inégalités socio-économiques en matière de santé constituent un défi de santé publique majeur dans les pays développés tout comme dans les pays en développement. Il existe peu de données factuelles sur les inégalités socio-économiques en matière de santé dans les différentes régions de la République islamique d'Iran.

Objectifs : La présente étude avait pour objectif de déterminer l'inégalité socio-économique de l'état de santé auto-évalué comme mauvais chez les adultes de la ville de Kermanshah, dans la partie occidentale de la République islamique d'Iran.

Méthodes : La présente étude transversale, basée sur un échantillonnage stratifié, a permis d'obtenir des données sur le statut socio-économique, les caractéristiques démographiques, les facteurs de risque comportemental et l'état de santé déterminé par auto-évaluation de 2040 adultes âgés de 18 ans et plus de la ville de Kermanshah. Un auto-questionnaire a été utilisé pour recueillir des données auprès des participants. L'indice de concentration $(C)$ et la courbe $\mathrm{C}$ ont été utilisés pour déterminer l'inégalité socio-économique de l'état de santé auto-évalué comme mauvais. Une analyse de décomposition de l'indice $\mathrm{C}$ a été effectuée afin d'identifier les facteurs expliquant l'inégalité socio-économique de l'état de santé auto-évalué comme mauvais.

Résultats : La prévalence brute et ajustée sur l'âge d'un état de santé auto-évalué comme mauvais était de 13,8\% et de $18,1 \%$, respectivement. L'indice C estimé pour la totalité de l'échantillon était de $-0,295$, ce qui indique que l'état de santé auto-évalué comme mauvais était concentré chez les pauvres. Selon les résultats de la décomposition, le statut socio-économique $(45,5 \%)$, un problème de santé chronique $(11,9 \%)$ et le tabagisme (7,3\%) étaient les principaux facteurs contribuant à la concentration d'une mauvaise santé auto-évaluée parmi ceux qui ont un statut socio-économique inférieur.

Conclusion : La concentration d'une mauvaise santé auto-évaluée parmi les pauvres dans la ville de Kermanshah mérite une attention politique. Les politiques visant à réduire les inégalités dans la répartition des richesses et les comportements à risque en matière de santé et à prévenir les problèmes de santé chroniques parmi les pauvres permettent d'atténuer les inégalités socio-économiques en matière de mauvaise santé auto-évaluée à Kermanshah.

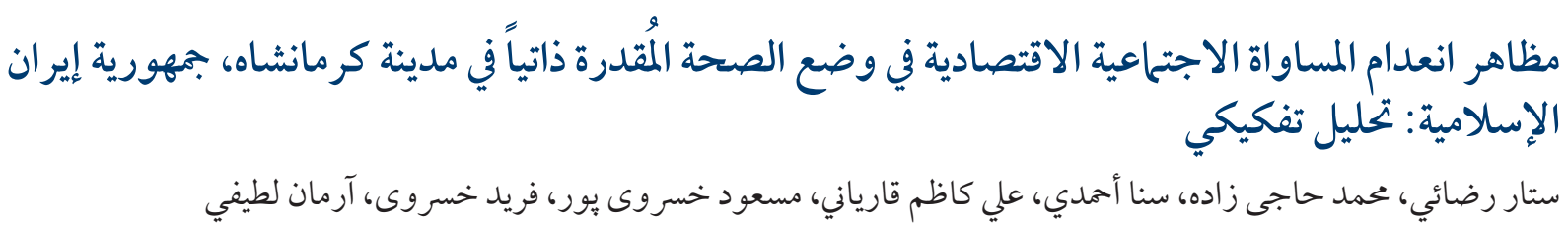

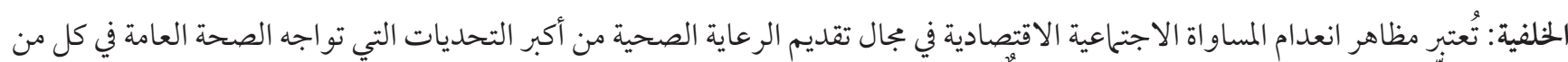

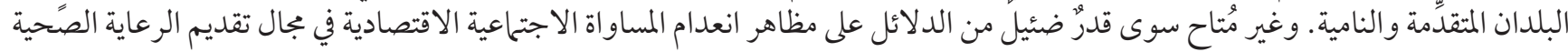
في ختتلف مناطق جمهورية إيران الإسلامية. وغئرة

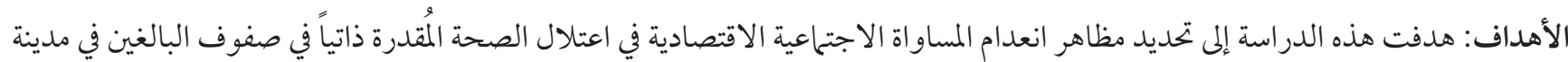

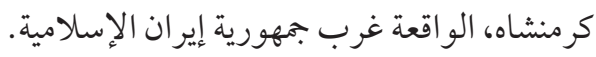

طرق البحث: اشتملت هذه الدراسة المقطعية على عينة طبقية من البيانات الخاصة بالوضع الاجتماعي الاقتصادي، والخصائل الخائص السكانية، وعو امل

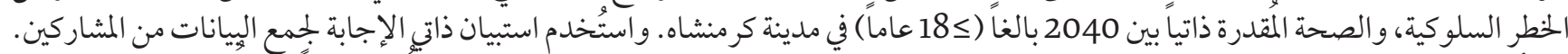

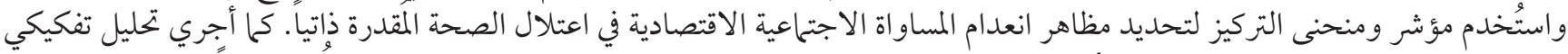

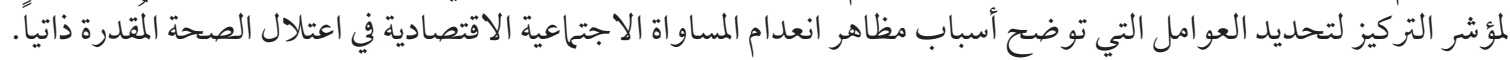




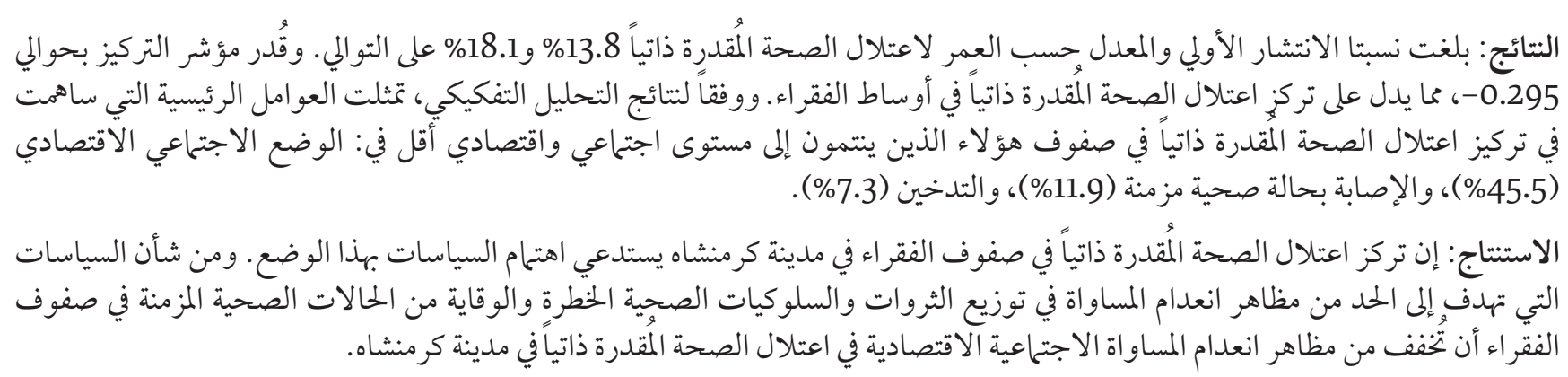

\section{References}

1. Starfield B. Equity in health. J Epidemiol Community Health. 2002;56(7):483-4. http://doi.org/10.1136/jech.56.7.483

2. Nedjat S, Hosseinpoor AR, Forouzanfar MH, Golestan B, Majdzadeh R. Decomposing socioeconomic inequality in self-rated health in Tehran. J Epidemiol Community Health. 2012;66(6):495-500. http://doi.org/10.1136/jech.2010.108977

3. Ostlin P, Braveman P, Dachs N; WHO Task Force on Research Priorities for Equity in Health; WHO Equity Team. Priorities for research to take forward the health equity policy agenda. Bull World Health Organ. 2005;83(12):948-53. http:// doi: /Soo4296862005001200018

4. Borg V, Kristensen TS. Social class and self-rated health: can the gradient be explained by differences in life style or work environment? Soc Sci Med. 2000;51(7):1019-30. http://doi:10.1016/s0277-9536(00)00011-3

5. Kunst AE, Bos V, Lahelma E, Bartley M, Lissau I, Regidor E, et al. Trends in socioeconomic inequalities in self-assessed health in 10 European countries. Int J Epidemiol. 2004;34(2):295-305. http://doi:10.1093/ije/dyh342

6. Smith JP. Unraveling the SES: health connection. Popul Dev Rev. 2004;30:108-32.

7. Smith JP. Healthy bodies and thick wallets: the dual relation between health and economic status. J Econ Perspect. 1999;13(2):145-66.

8. Sözmen K, Baydur H, Simsek H, Ünal B. Decomposing socioeconomic inequalities in self assessed health in Turkey. Int J Equity Health. 2012;11(1):73. http://doi:10.1186/1475-9276-11-73

9. Singh-Manoux A, Dugravot A, Shipley MJ, Ferrie JE, Martikainen P, Goldberg M, et al. The association between self-rated health and mortality in different socioeconomic groups in the GAZEL cohort study. Int J Epidemiol. 2007;36(6):1222-8. http:// doi:10.1093/ije/dym170

10. Layes A, Asada Y, Kephart G. Whiners and deniers-what does self-rated health measure? Soc Sci Med. 2012;75(1):1-9. http:// doi:10.1016/j.socscimed.2011.10.030

11. Jylhä M. What is self-rated health and why does it predict mortality? Towards a unified conceptual model. Soc Sci Med. 2009;69(3):307-16. http://doi:10.1016/j.socscimed.2009.05.013

12. Kondo N, van Dam RM, Sembajwe G, Subramanian S, Kawachi I, Yamagata Z. Income inequality and health: the role of population size, inequality threshold, period effects and lag effects. J Epidemiol Community Health. 2012;66(6):e11. http://doi:10.1136/ jech-2011-200321

13. Kawada T, Wakayama Y, Katsumata M, Inagaki H, Otsuka T, Hirata Y, et al. Patterns in self-rated health according to age and sex in a Japanese national survey, 1989-2004. Gender medicine. 2009;6(1):329-34. http://doi:10.1016/j.genm.2009.04.001

14. Rezaei S, Hajizadeh M, Khosravipour M, Khosravi F, Rezaeian S. Socioeconomic Inequalities in Poor Health-Related Quality of Life in Kermanshah, Western Iran: A Decomposition Analysis. J Res Health Sci. 2018;18(1):e00405.

15. Power C, Matthews S, Manor O. Inequalities in self-rated health: explanations from different stages of life. Lancet. 1998;351(9108):1009-14. http://doi:10.1016/S0140-6736(97)11082-0

16. Asfar T, Ahmad B, Rastam S, Mulloli TP, Ward KD, Maziak W. Self-rated health and its determinants among adults in Syria: a model from the Middle East. BMC Public Health. 2007;7(1):177. http://doi:10.1186/1471-2458-7-177

17. Murray CJ, Evans D, editors. Health systems performance assessment: debates, methods and empiricism. Geneva: World Health Organization; 2003 (https://apps.who.int/iris/handle/10665/42735, accessed 22 August 2018).

18. Statistical Center of Iran. Population and housing censuses; 2016 (https://www.amar.org.ir/english/Population-and-Housing-Censuses, accessed 2 January 2020).

19. Subramanian SV, Ertel K. Self-rated health may be adequate for broad assessments of social inequalities in health. Int J Epidemiol. 2009;38(1):319-20. http://doi:10.1093/ije/dyn241

20. Lundberg O, Manderbacka K. Assessing reliability of a measure of self-rated health. Scand J Soc Med. 1996;24(3):218-24. http:// doi:10.1177/140349489602400314

21. Wagstaff A, Paci P, Van Doorslaer E. On the measurement of inequalities in health. Soc Sci Med. 1991;33(5):545-57. https://doi. org/10.1016/0277-9536(91)90212-U 
22. Kakwani N, Wagstaff A, Van Doorslaer E. Socioeconomic inequalities in health: measurement, computation, and statistical inference. J Econom. 1997:87-103. http://doi:10.1016/j.jhealeco.2008.09.004

23. Wagstaff $\mathrm{A}$. The bounds of the concentration index when the variable of interest is binary, with an application to immunization inequality. Health Econ. 2005;14(4):429-32. http://doi:10.1002/hec.953

24. Vyas S, Kumaranayake L. Constructing socioeconomic status indices: how to use principal components analysis. Health Policy Plan. 2006;21(6):459-68. http://doi:10.1093/heapol/czlo29

25. Wagstaff A, Van Doorslaer E, Watanabe N. On decomposing the causes of health sector inequalities with an application to malnutrition inequalities in Vietnam. J Econom. 2003;112(1):207-23. https://doi.org/10.1016/S0304-4076(02)00161-6

26. Cai J, Coyte PC, Zhao H. Decomposing the causes of socioeconomic-related health inequality among urban and rural populations in China: a new decomposition approach. Int J Equity Health. 2017;16(1):128. http://doi:10.1186/s12939-017-0624-9

27. Darviri C, Artemiadis AK, Tigani X, Alexopoulos EC. Lifestyle and self-rated health: a cross-sectional study of 3,601 citizens of Athens, Greece. BMC Public Health. 2011;11(1):619. http://doi:10.1186/1471-2458-11-619

28. Ahmad K, Jafar TH, Chaturvedi N. Self-rated health in Pakistan: results of a national health survey. BMC Public Health. 2005;5(1):51. http://doi:10.1186/1471-2458-5-51

29. Demirchyan A, Thompson ME. Determinants of self-rated health in women: a population-based study in Armavir Marz, Armenia, 2001 \& 2004. Int J Equity Health. 2008;7(1):25. http://doi:10.1186/1475-9276-7-25

30. Perlman F, Bobak M. Determinants of self rated health and mortality in Russia-are they the same? Int J Equity Health. 2008;7(1):19. http://doi:10.1186/1475-9276-7-19

31. Dowd JB, Zajacova A. Does the predictive power of self-rated health for subsequent mortality risk vary by socioeconomic status in the US? Int J Epidemiol. 2007;36(6):1214-21. http://doi:10.1093/ije/dym214

32. Xie E. Income-related inequalities of health and health care utilization. Fron Econ China. 2011;6(1):131-56. https://doi.org/10.1007/ s11459-011-0125-5

33. Gilmore AB, McKee M, Rose R. Determinants of and inequalities in self-perceived health in Ukraine. Soc Sci Med. 2002;55(12):2177-88. http://doi:10.1016/s0277-9536(01)00361-6

34. Laaksonen M, Rahkonen O, Martikainen P, Lahelma E. Socioeconomic position and self-rated health: the contribution of childhood socioeconomic circumstances, adult socioeconomic status, and material resources. Am J Public Health. 2005;95(8):1403-9. http://doi:10.2105/AJPH.2004.047969

35. Honjo K, Kawakami N, Takeshima T, Tachimori H, Ono Y, Uda H, et al. Social class inequalities in self-rated health and their gender and age group differences in Japan. J Epidemiol. 2006;16(6):223-32. http://doi:10.2188/jea.16.223

36. Klein J, Hofreuter-Gätgens K, Lüdecke D, Fisch M, Graefen M, von dem Knesebeck O. Socioeconomic status and health-related quality of life among patients with prostate cancer 6 months after radical prostatectomy: A longitudinal analysis. BMJ Open. 2016;6(6):e010968. http://doi:10.1136/bmjopen-2015-010968

37. Huguet N, Kaplan MS, Feeny D. Socioeconomic status and health-related quality of life among elderly people: results from the Joint Canada/United States Survey of Health. Soc Sci Med. 2008;66(4):803-10. http://doi:10.1016/j.socscimed.2007.11.011 